\title{
Sickle cell trait in orthopaedic surgery: A real issue or just a bogeyman
}

Background: Sickle cell disease is a hereditary blood disease characterized by the production of abnormal haemoglobin. HbS precipitates in the red cells under specific circumstances. The sickle cell trait (SCT), long considered an asymptomatic, condition, is instead associated with several complications. SC carriers are under physical stress more predisposed to develop certain morbidities such as pulmonary embolism, deep vein thrombosis, rhabdomyolysis and heat-associated collapse. An intense physical stress associated with the $\mathrm{HbS}$ carrier condition can lead to sudden death. Major surgeries, and especially orthopedic surgery, are physically stressful events. A targeted screening of high-risk patients could be useful for several advantages.

Keywords: sickle cell trait • complications $\bullet$ screening

\section{Introduction}

Sickle cell disease

The sickle cell disease (SCD) is a hereditary blood disease characterized by the production of an abnormal haemoglobin, the sickle hemoglobin $(\mathrm{HbS})$, due to a mutation in the $\beta 1$-globine gene, in the short arm of the chromosome 11 . HbS precipitates in the red cells under specific circumstances, forming polymers that distort the cells into the characteristic sickle shape: this process is known as sickling. Vaso-occlusion and hemolytic anemia are the major features of the sickle hemoglobinopathies. In sickle cell disease affected individual are either homozygous for the sickle hemoglobin (HbS) or compound heterozygous for the $\mathrm{HbS}$ and another beta globin mutation (HbC, HbS- $\beta$ thalassemia). Several factors influence the susceptibility of red cells to sickle: the $\mathrm{HbS}$ and $\mathrm{HbF}$ concentrations, the HbS haplotype, the $\beta$ thalassemia gene deletion the oxygen content of the inspired air, the cardiac and pulmonary status [1]. Other factors such as dehydration, infection, acidosis and hypothermia may increase red blood cell sickling [2]. Four main haplotypes, representing four different mutations have been identified (the Asian or Arabo-Indian haplotype, the Benin haplotype, the Senegal haplotype and the Bantu or CAR haplotype). The haplotype influences the sickle cell disease severity: the Bantu haplotype is associated with the most severe disease and the Senegal haplotype, with the least severe disease [2]. Bone involvement is the commonest clinical manifestation of sickle-cell disease both in the acute setting such as painful vaso-occlusive crises, and as a source of chronic, progressive disability such as avascular necrosis Figure 1 [3].

\section{Sickle cell trait}

The sickle cell trait (SCT), long considered an asymptomatic, benign condition, is instead associated with several complications [4]. The sickle-cell trait (SCT) occurs when a mutated $S \beta 1$-globine and a normal $\beta A$-globin gene are inherited (HbAS). HbS carriers are approximately 300 million people worldwide [2], with the highest concentration in Africa, Middle East, India and the Mediterranean region. Recently its incidence has increased in Europe and North America because of the high rate of migration from areas in which the disease is prevalent [5]. Traditionally, sicklecell trait has been viewed as a non-disease, partially protective against falciparum malaria [6], without any of the complications and symptoms characteristic of the sickle cell disease. Due to the almost completely asymptomatic nature of the condition sickle cell trait is generally a laboratory diagnosis. Hemoglobin

\author{
Francesco Pisanu', Gianfilippo \\ Caggiari $^{* 1}$, Sebastiano Ortu', \\ Maria Luisa Satta², Carlo Doria ${ }^{1}$ \\ 'Orthopaedic Department, University of \\ Sassari, Italy \\ ${ }^{2}$ Department of Anaesthesia, Intensive Care \\ and Pain Management -ASSL Olbia, Italy \\ *Author for correspondence: \\ gianfilippocaggiari@gmail.com
}




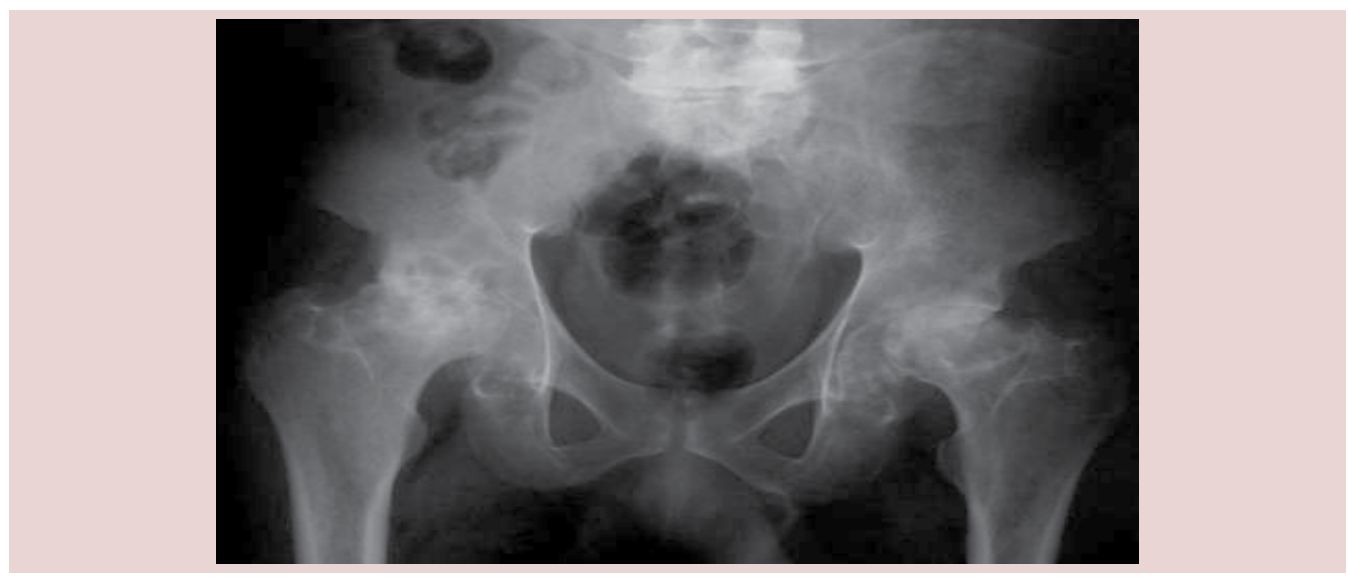

Figure 1. Bone involvement is the most common clinical manifestation of sickle cell disease.

levels, red cell morphology, red cell indices, and the reticulocyte count are entirely normal in patients with sickle cell trait [7], and irreversibly sickled cells (ISCs) are not normally present in the peripheral blood smear. The diagnosis of sickle cell trait is made by demonstrating the presence of significant quantities of HbS. Hemoglobin determination by high-pressure liquid chromatography (HPLC) is the method most commonly used to diagnose HbAS [8]. Although sickle-cell trait is a benign condition in a majority of affected individuals, occasionally, it can be associated with significant morbidity and mortality. Increased red blood cell sickling and polymerization can occur in sickle cell trait under several conditions: severe tissue hypoxia, acidosis, increased viscosity, dehydration, and hypothermia. Several observational studies and small case series [9-17] describe the morbidity of sickle cell trait, and a recent review [2] grouped the complications of sickle cells trait on the basis of the strength and specificity of observed associations. The complications are grouped as: "definite", "probable", "possible" and "unproven or unlikely". The group of definite associations includes: renal medullary cancer, hematuria both microscopic and macroscopic, renal papillary necrosis, hyposthenuria, splenic infarction, exercise-related sudden death, exercise-related rhabdomyolysis. Groups of probable and possible co-morbidity include: venous thromboembolic events (deep vein thrombosis or pulmonary embolism), fetal loss, acute chest syndrome, and proliferative retinopathy. Between the unproven co-morbidity there are anemia, stroke, higher prevalence of diabetic retinopathy and albuminuria, leg ulcers, avascular necrosis of the femoral head, and liver necrosis. The assignment of complication into these groups was not based on a systematic review of the literature and thus the importance of some of the condition may have been overrated and others may have been underrated [18]. SC carriers are under physical stress more predisposed to develop certain morbidities such as pulmonary embolism, deep vein thrombosis, rhabdomyolysis and heat associated collapse. Several screening performed on athletes and soldiers also report a much more serious complication: an intense physical stress associated with the $\mathrm{HbS}$ carrier condition can lead to sudden death [19-22]. Major surgeries, and especially orthopedic surgery, are physically stressful events Figure 2. As far as the treatment of hemoglobinopathies is of a medical nature, the surgeon should be aware of the possible complications arising from being $\mathrm{HbS}$ carrier.

\section{SC clinical implication in major orthopedic} surgery

An increased complication rate of orthopedic surgery in SCD compared with the general orthopedic population has been reported in the literature [23]. We have not been able to find studies showing a higher incidence of complication in major orthopedic surgery in patients with SCT nevertheless adequate knowledge of the condition and precautions to avoid factors predisposing to red cell sickling could contribute to the reduction in morbidity and mortality theoretically associated with surgery stress not only in SCD but also in $\mathrm{HbS}$ carriers.

\section{Importance of screening and research}

The absence of a screening program of this almost always asymptomatic condition, so widespread in the world and more and more also in not typically affected countries, can lead to an underestimation of its frequency in patients undergoing surgery for diseases not clearly linked to the SC trait. 


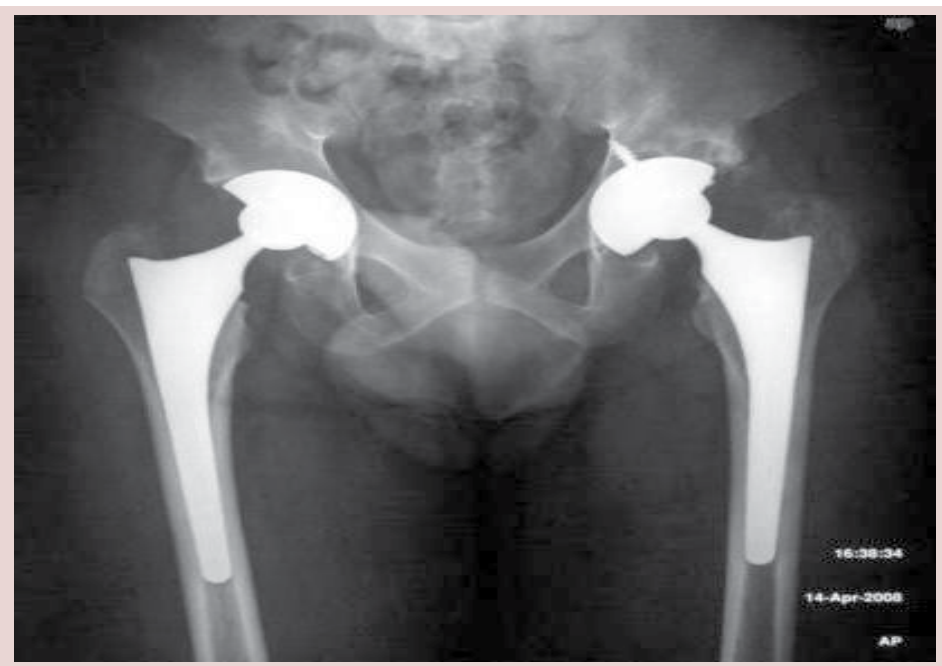

Figure 2. Radiographic image of bilateral hip replacement with total hip arthroprosthesis for avascular necrosis of the femoral head in SCT.

Screening programs for SC trait have been adopted in at-risk populations such as military and athletes, triggering controversy on the real advantage of the awareness of this condition at the expense of unjustified social and employment discrimination [24-27]. This discrimination is even more hateful, as the mutation is typical of certain ethnic groups, and so often taking on a racial connotation [28-29]. In health care however, a targeted screening of high-risk patients could be useful for several advantage:

- a more comprehensive assessment and a faster recognition of possible complications intra and perioperative by the medical and nursing staff;

- a greater awareness of the patients about their increased risks of complications;

- a theoretical reduction (until proven otherwise) of the risk of complications through a more careful monitoring of acid-base balance, hydration, temperature, oxygen saturation;

- acquisition of more clinical data to ensure a less empirical approach and to lead to an evidence based management.

An appropriate screening technique is mandatory to ensure accuracy and reliability of subsequent studies. The sickle solubility test detects the presence or absence of sickle hemoglobin, but cannot differentiate individuals with SCD and SCT and can be falsely negative in infants with high hemoglobin F or in individuals with very low percentage $\mathrm{HbS}(<10 \%)$; comigration of certain rare hemoglobin variants with $\mathrm{HbS}$ may obscure the diagnosis with standard electrophoresis; high-performance liquid chromatography (HPLC) can provide discrimination and relative quantification of hemoglobin, allowing for differentiation of SCT from SCD syndromes [29]. In clinical setting HPLC is the method most commonly used to diagnose HbAS [8] and has also been adopted for hemoglobinopathy screening by many reference laboratories owing to its ability to precisely quantify hemoglobin components [29]. Public education about SCT and SCD, accurate SCT testing, transparency of screening protocols and high-quality research initiatives are also mandatory to avoid some critical issue emerged in the past related to stigmatization and concern for social or occupational implications [29].

\section{Conclusion}

The SCT condition is not exempt from specific complications. Some of these complications occur as a result of physical stress and adverse environmental conditions. The literature does not report any special precautions for surgical patients with SC trait, but shows an increased complication rate in orthopedic surgery in sickle cell disease. Carrier status is widespread in the world, but for its frequent asymptomatic nature is often unknown by the patient. The patient's unawareness of their state of $\mathrm{HbS}$ carrier and the lack of screening programs can lead to an underestimation of surgical complications actually associated with the SCT. Waiting for more significant studies on possible surgical complications of SCT, we recommend to perform targeted screening on patients from high-risk populations for this mutation. A more 
complete clinical picture could lead to a greater awareness of risks and to a reduction of associated complications. The analysis of a greater number of data through adequately-powered studies in the future may lead to an evidence based management.

\section{References}

1. Steinberg MH, Sebastiani P. Genetic modifiers of sickle cell disease. Am. J. Hematol. 87, 795-803 (2012).

2. Tsaras G, Owusu AA, Boateng FO et al. Complications Associated with Sickle Cell Trait: A Brief Narrative Review. Am. J. Med. 122, 507-512 (2009).

3. Almeida A, Roberts I. Bone involvement in sickle cell disease. Br. J. Haematol. 129, 482-490 (2005).

4. Key NS, Derebail VK. Sickle cell trait: novel clinical significance. Hematology. Am. Soc. Hematol. Educ. Program. 418-422 (2010).

5. Ballardini E, Tarocco A, Marsella M et al. Universal neonatal screening for sickle cell disease and other haemoglobinopathies in Ferrara, Italy. Ital. J. Pediatr. $38,32(2012)$

6. Goldsmith JC, Bonham VL, Joiner $\mathrm{CH}$ et al. Framing the research agenda for sickle cell trait: building on the current understanding of clinical events and their potential implications. Am. J. Hematol. 87(3), 340-346 (2012).

7. John N. A Review of Clinical Profile in Sickle Cell Traits. Oman. Med. J. 25(1), 3-8 (2012)

8. Wilson CI, Hopkins PL, Cabello IB et al. The Peripheral Blood Smear in Patients With Sickle Cell Trait: A Morphologic Observation. lab. Med. 31(8), 445-447 (2000).

9. Watanabe IC, Billis A, Guimares MS et al. Renal medullary carcinoma: report of seven cases from Brazil. Mod. Pathol. 20, 914-920 (2007).

10. Noguera IWG, Hibshoosh H, Papadopoulos KP. Renal medullary carcinoma: case report and review of the literature. Am. J. Clin. Oncol. 26, 489-492 (2003).

11. Franlin QJ, Compeggie M. Splenic syndrome in sickle cell trait: four case presentations and a review of the literature. Mil. Med. 164, 230-233 (1999).

12. Cooley JC, Peterson WL, Engel CE et al. Clinical triad of massive splenicinfarction, sicklemia trait, and high altitude flying. J. Am. Med. Assoc. 154, 111-113 (1954).

13. Dourakis SP, Alexopoulou C, Kaloterakis A et al. Acute chest syndrome in sickle-cell trait. Two case reports in persons of Mediterranean origin and review of the literature. Eur. J. Intern. Med. 15, 248-250 (1994).
14. Lopeza MJ, Coronasb JS, Ordnezc AV et al. Infartos óseos con rasgo drepanocítico. Rev. Clin. Esp. e1-e3 (2012).

15. Ahmad A. Retinopathy in ophthalmologically asymptomatic patients with abnormal hemoglobin. Ann. Ophthalmol. 11, 365-369 (1979).

16. Taylor PW, Thorpe WP, Trueblood MC. Osteonecrosis in sickle cell trait. J. Rheumatol. 13(3), 643-6 (1986).

17. Perumal JR, Corbett M. Avascular necrosis of the femoral head in sickle cell trait. Rheumatol. Rehabil. 17(2), 113 (1978).

18. Ballas SK, Kesen MR, Goldberg MF et al. Beyond the Definitions of the Phenotypic Complications of Sickle Cell Disease: An Update on Management. Scientific World J. 2012, 949535 (2012).

19. Jones SR, Binder RA, Donowho EM Jr. Sudden death in sickle cell trait. N. Engl. J. Med. 83(22), 12291231(1970).

20. Thompson PD, Funk EH, Carleton RA et al. Incidence of death during jogging in Rhode Island from 1975 through 1980. JAMA 247(18), 2535-2538 (1982).

21. Sullivan LW. The risks of sickle cell trait: Caution and common sense. N. Engl. J. Med. 317, 830-31(1987).

22. Folsom AR, Tang W, Roetker NS et al. Prospective study of sickle cell trait and venous thromboembolism incidence. J. Thromb. Haemost. 13(1), 2-9 (2015).

23. Vichinsky EP, Neumayr DL, Haberkern C et al. The Perioperative Complication Rate of Orthopedic Surgery in Sickle Cell Disease: Report of the National Sickle Cell Surgery Study Group. Am. J. Hematol. 62, 129-138 (1999).

24. Mitchell BL. Sickle cell trait and sudden deathbringing it home. Natl. Med. Assoc. 99, 300-305 (2007).

25. Bonham VL, Dover GJ, Brody LC. Screening student athletes for sickle cell trait-a social and clinical experiment. N. Engl. J. Med. 363, 997-999 (2010).

26. Steinberg MH. In the clinic: sickle cell disease. Ann. Intern. Med. 155(5), ITC31-ITC15 (2011).

27. Johnson LN. Sickle cell trait: an update. J. Natl. Med. Assoc. 74(8), 751-757 (1982).

28. Markel H. The stigma of disease: implications of genetic screening. Am. J. Med. 93(2), 209-215 (1992).

29. Naik RP, Haywood C. Sickle cell trait diagnosis: clinical and social implications. Hematology. Am. Soc. Hematol. Educ. Program.160-167 (2015). 